\title{
Activation of NK cells in male cancer survivors by fucoidan extracted from Cladosiphon okamuranus
}

\author{
TAKEAKI NAGAMINE ${ }^{1}$, KIZUKU KADENA ${ }^{2}$, MAKOTO TOMORI ${ }^{2}$, \\ KATSUYUKI NAKAJIMA ${ }^{3}$ and MASAHIKO IHA ${ }^{2}$
}

\author{
${ }^{1}$ Department of Nutrition, Takasaki University of Health and Welfare, Takasaki, Gunma 370-0036; \\ ${ }^{2}$ South Product Co., Ltd., Uruma, Okinawa 904-2234; ${ }^{3}$ Department of Clinical Laboratory Medicine, \\ Gunma University Graduate School of Medicine, Maebashi, Gunma 371-8514, Japan
}

Received December 19, 2018; Accepted September 25, 2019

DOI: $10.3892 / \mathrm{mco} .2019 .1943$

\begin{abstract}
Cancer survivors are highly motivated to seek information about the use of dietary supplements and complementary nutritional therapies to improve their quality of life. Fucoidan, a sulfated polysaccharide extracted from brown marine alga, exhibits a wide range of bioactivities, including anticancer activity. As natural killer (NK) cells serve an important role in defenses against tumor cells, the present study examined the effects of fucoidan extracted from Cladosiphon Okamuranus on NK cell activity in cancer survivors. A prospective, open-label clinical study was conducted on cancer survivors treated with fucoidan via oral administration; 11 cancer survivors with a performance status of 0 or 1 participated and consumed $3 \mathrm{~g}$ of fucoidan for 6 months. No significant changes were observed in the mean activities of NK cells in total subjects following the ingestion of fucoidan. An analysis of each sex revealed that NK cell activity was significantly increased by the ingestion of fucoidan in male, yet not female subjects. Serum fucoidan levels were markedly increased following the ingestion of fucoidan and the peak levels ranged between 30 and $198 \mathrm{ng} / \mathrm{ml}$. Tumor markers remained within the reference range during the trial period in subjects, in whom primary tumors were eradicated by treatment. The basal values of tumor markers were elevated in three cases; tumor markers were increased in two cases and decreased in one by the ingestion of fucoidan. These findings suggest that fucoidan enhances the activation of NK cells in male cancer survivors.
\end{abstract}

Correspondence to: Dr Takeaki Nagamine, Department of Nutrition, Takasaki University of Health and Welfare, 37-1 Nakaorui-machi, Takasaki, Gunma 370-0033, Japan

E-mail: mine@gunma-u.ac.jp

Dr Makoto Tomori, South Product Co., Ltd., 12-75 Suzaki, Uruma, Okinawa 904-2234, Japan

E-mail: morimakoto@gmail.com

Key words: fucoidan, natural killer cells, cancer survivors, tumor marker, sulfated polysaccharide, Cladosiphon Okamuranus

\section{Introduction}

Fucoidan is a complex sulfated polysaccharide that is mostly found in brown marine algae. Fucoidan exhibits a broad spectrum of biological activities, including anti-inflammatory, immunomodulatory, antiviral, antioxidant, and anti-tumor activities (1-4). Previous studies reported a potential role for fucoidan as an anticancer agent based on its proven anticancer and anti-metastatic effects in vivo and in vitro (4-7). The mechanisms underlying the anticancer effects of fucoidan have not yet been elucidated in detail; however, immune modulation is one of the most promising areas for the anticancer efficacy of fucoidan $(8,9)$.

A cancer survivor is defined as anyone who has been diagnosed with cancer, from the time of diagnosis and throughout the remainder of their lifespan (10). Many cancer survivors are highly motivated to seek information about food choices, physical activity, dietary supplement use, and complementary nutritional therapies in order to improve their response to treatment, speed of recovery, and quality of life and also to reduce their risk of recurrence (11).

A clinical trial was performed on fucoidan in patients with advanced colon cancer. Ikeguchi et al reported that the ingestion of $4.05 \mathrm{~g}$ per day of fucoidan derived from Cladosiphon okamuranus reduced the clinical toxicity indicator 'fatigue' in patients receiving conventional chemotherapy (12). Furthermore, patients administered fucoidan tolerated more cycles of chemotherapy. A recent clinical trial on fucoidan in patients with different types of advanced cancers identified the responsiveness of interleukin (IL)-1 $\beta$ as a significant independent prognostic factor. However, natural killer (NK) cell activity was not affected by a four-week treatment with fucoidan derived from C. novae-caledoniae Kylin (13).

NK cell cytotoxic activity represents an innate immune component that plays an important role in defenses against tumor cells (14). NK cells recognize and induce the lysis of tumor cells without prior sensitization. An epidemiologic survey of 11-year follow up shows a link between low NK cell activity in peripheral blood and increased cancer risk in adults (15). We herein examined the effects of fucoidan extracted from C. Okamuranus on NK cell activity in cancer survivors. 


\section{Patients and methods}

Subjects. Cancer survivors willing to participate in the present study were recruited from 4 medical clinics (Ono Clinic, Kobe City; Hoshi Clinic, Maebashi City; Takeichi Clinic, Odawara City and Daido Chuo Clinic, Naha City) in Japan between June 2016 and May 2017. Eleven patients who met the following inclusion criteria were enrolled: i) cancer survivors following surgical resection, radiation therapy, chemotherapy, and radiofrequency ablation (RFA) without recurrence and metastasis; ii) cancer survivors receiving chemotherapy without metastasis and iii) cancer survivors before therapy without metastasis. Exclusion criteria are as follows: i) cancer survivors with a performance status of 2 , 3 and 4; ii) cancer survivors with obvious recurrence and metastasis at enrollment and iii) cancer survivors complicated with liver cirrhosis, renal insufficiency, advanced heart failure and immunodeficiency.

The diagnosis of cancer was confirmed by characteristic pathologies (Table I). Demographic characteristics are shown in Table II. All subjects were ambulatory as an outpatient with a normal food intake during the trial periods. Although the primary cancer lesions markedly varied, recurrence and metastasis were confirmed to be absent by an examination using computed tomography (CT) and/or magnetic resonance imaging (NRI) before enrollment. Primary tumor lesions of seven patients (Case 1, 2.3.4.5.8 and 9) were completely eradicated by surgical operation or radiation therapy. The period from cancer therapy to fucoidan trial was between 6 months and 8 years ( 3.0 years on the average).

Two cases (Cases 6 and 11) were undergoing standard chemotherapy before the administration of fucoidan. Case 6 took erlotinib for two years and Case 11 took irinotecan for five years. Case 7 was awaiting surgical resection without chemotherapy. Case 10 was treated with a surgical operation for colon cancer two years before the clinical trial.

The present study was performed in accordance with the Declaration of Helsinki. The study protocol was approved by the Ethics Committee of South Product Co., Ltd.

Fucoidan treatment. Fucoidan extracted from Okinawa mozuku (C. okamuranus) was used in the present study. The main molecular weight of fucoidan was $28.8 \mathrm{kDa}$, containing $70 \mathrm{mg} / \mathrm{ml}$ of L-fucose and $10 \mathrm{mg} / \mathrm{ml}$ of sulfate (16). Subjects were orally administered $50 \mathrm{ml}$ of a drink that contained $1.5 \mathrm{~g}$ of fucoidan twice daily for 6 months. The drink was prepared by South Product Co. Subjects took a meal without dietary restriction during the trial period. Subjects receiving medicine(s) continued with the same treatment as before, and anti-cancer drugs were unchanged during the trial period. Complementary and alternative medicine (CAM) was prohibited during the trial period, because it may affect NK cell activity and/or absorption of fucoidan. We checked use of CAM when subjects attended a clinic.

Clinical assessment. The clinical status of subjects was recorded every month during the ingestion of fucoidan. Subjects were asked about any new symptoms or changes since the introduction of fucoidan. Fucoidan was withheld if subjects developed adverse events and laboratory toxicity.
Endpoints. NK cells are the prototype of innate lymphoid cells with potent cytolytic function that provide immune surveillance against cancer; whereas, the effect of fucoidan on NK cell activity remains to be fully elucidated in cancer survivors. The primary endpoint was changes in NK cell activity and immunoglobulin titers because we focused on the immunomodulatory effects of fucoidan. We have already performed a randomized double-blind trial of fucoidan in healthy Japanese volunteers, in which oral administration of fucoidan for 12 weeks significantly increased NK cell activity in male, but not in female volunteers (unpublished data). In order to certify the finding, we herein examined NK cell activity based on sex.

Although there are no specific tumor markers used in cancer screening, some markers can be used to assist in making a diagnosis and determining a prognosis. They can be used to follow in cases where the diagnosis is cancer through monitoring of the disease recurrence and/or evaluating the response to therapy. In order to elucidate the effect of fucoidan on anti-tumor activity, the secondary endpoint was changes in tumor markers during the trial period.

Metabolism of fucoidan for long period of oral intake was not determined yet. The third endpoint was fucoidan absorption following its oral administration. These endpoints were monitored at the outpatient clinic using blood sampling before and every six months during the ingestion of fucoidan. A urinalysis was also simultaneously performed.

Blood tests. Blood samples were drawn to assess hematological markers (white blood cells, neutrophils, lymphocytes, monocytes, eosinophils, red blood cells, hemoglobin, and platelets); liver function (albumin, bilirubin, alkaline phosphatase, alanine aminotransferase, aspartate aminotransferase, $\gamma$-glutamyl transferase); lipids (triglycerides, HDL cholesterol, LDL cholesterol); renal function tests (blood urea nitrogen, creatinine); uric acid; electrolytes $(\mathrm{Na}, \mathrm{K}, \mathrm{Cl}, \mathrm{Ca})$; $\mathrm{NK}$ cell activity; immunoglobulin titers; tumor markers; and fucoidan concentrations. Clinical biochemical and hematological parameters were assayed using commercially available kits. Albumin was measured by the modified PCP method (KAINOS Laboratories, Inc.). Total bilirubin was measured by vanadic acid oxidation method (Wako Laboratory Chemical Co., Ltd.). Aspartate aminotransferase (AST), alanine aminotransferase (ALT), alkaline phosphatase (ALP) and $\gamma$-glutamyl transferase $(\gamma$-GTP) were measured by the JSCC transferable method (Kanto Chemical Co., Inc.). HDLchoresterol and LDL choresterol were measured by selective solubilization method (Kyowa Medex Co., Ltd.). Triglycerides (TG) was measured by GK:GP-elimination of free glycerol method (Sekisui MedicalCo., Ltd.). Blood urea nitrogen (BUN) was measured by urease-LED method (Kanto Chemical Co., Inc.). Creatinine (Cr) was measured by enzymatic method (Sekisui Medicals Co., Ltd.). Uric acid (UA) was measured by uricase-peroxidase method (KAINOS Laboratories, Inc.). Sodium (Na) and Potassium (K) were measured by ion selective electrode method (JOEL Ltd.). Calcium (Ca) was measured by Arsenazo III method (KAINOS Laboratories, Inc.). Complete blood count was measured by the automated method (Sysmex Corp.).

NK cell activity: NK cell activity was evaluated in the k-562 cell line (Dainippon Pharmaceutical Co.) marked with 
Table I. Characteristics and diagnosis of subjects.

\begin{tabular}{|c|c|c|c|c|}
\hline Case & Sex & Age (years) & Diagnosis & Treatment \\
\hline 1 & Male & 67 & Pharyngeal cancer & Post-surgical resection \\
\hline 2 & Male & 81 & Hepatocellular carcinoma & Post-radiofrequency ablation \\
\hline 3 & Male & 78 & Hepatocellular carcinoma & Post-radiofrequency ablation \\
\hline 4 & Male & 70 & Renal cell cancer & Post-surgical resection \\
\hline 5 & Male & 71 & Colon cancer & Post-surgical resection \\
\hline 6 & Male & 74 & Lung cancer & Undergoing chemotherapy (Erlotinib) \\
\hline 7 & Male & 76 & Prostate cancer & Pre-surgical operation \\
\hline 8 & Female & 58 & Cervical cancer & Post-surgical resection \\
\hline 9 & Female & 52 & Breast cancer & Post-surgical resection \\
\hline 10 & Female & 56 & Colon cancer & Post-surgical resection \\
\hline 11 & Female & 70 & Adult T-cell leukemia & Undergoing chemotherapy (Irinotecan) \\
\hline
\end{tabular}

Table II. Demographic characteristics of subjects.

\begin{tabular}{clcccc}
\hline Case & Sex & Age (years) & Height $(\mathrm{cm})$ & Body weight $(\mathrm{kg})$ & Performance status \\
\hline 1 & Male & 67 & 171 & 68 & 0 \\
2 & Male & 81 & 161 & 71 & 0 \\
3 & Male & 78 & 167 & 62 & 0 \\
4 & Male & 70 & 172 & 63 & 0 \\
5 & Male & 71 & 168 & 64 & 0 \\
6 & Male & 74 & 162 & 71 & 0 \\
7 & Male & 76 & 163 & 54 & 0 \\
8 & Female & 58 & 158 & 50 & 0 \\
9 & Female & 52 & 167 & 45 & 0 \\
10 & Female & 56 & 152 & 54 & 1 \\
11 & Female & 70 & 153 & & 0 \\
\hline
\end{tabular}

${ }^{51} \mathrm{Cr}$ using a cytotoxicity test for $3.5 \mathrm{~h}$ (17). Blood samples taken from the cubital vein were collected into heparinized tubes. After the centrifugation of blood samples with a lymphocyte separation medium, interface mononuclear cells were collected and suspended at a cell density of $1 \times 10^{6} / \mathrm{ml}$ in RPMI-1640 medium (IBL) and supplemented with $10 \%$ FBS. Peripheral blood monocytes $\left(2 \times 10^{5}\right.$ cells) were added to round-bottomed 96-well microplates containing ${ }^{51} \mathrm{Cr}$-labeled target cells $\left(1 \times 10^{4}\right.$ cells) in $0.2 \mathrm{ml}$ of RPMI-1640 medium supplemented with $10 \%$ FBS. The effector cell/target cell ratio was 20. After centrifugation at $800 \mathrm{r} / \mathrm{min}$ for $5 \mathrm{~min}$ using an exclusive centrifuge for microplates, cells were incubated at $37^{\circ} \mathrm{C}$ for $3.5 \mathrm{~h}$ under $50 \mathrm{ml} / 1 \mathrm{CO}_{2}$ in air. After the incubation, the culture supernatant was harvested using PET $\Sigma$-96 (Sohken; Tokyo, Japan), and radioactivity was evaluated using a gamma counter (1272 clinigamma; Wallac). The percentage of cytotoxicity was calculated as follows: $\%$ cytotoxicity $=\left(\right.$ experimental ${ }^{51} \mathrm{Cr}$ release-spontaneous ${ }^{51} \mathrm{Cr}$ release)/(maximal ${ }^{51} \mathrm{Cr}$ release-spontaneous ${ }^{51} \mathrm{Cr}$ release) $\mathrm{x} 100$.

$\operatorname{IgG}$ and $\operatorname{Ig}$ A titers were measured using a turbidimetric immunoassay, and the IgE titer was assessed using the FEIA method.
Tumor markers were assayed as follows. Cytokeratin fragment (Cyfra) 21-1 (18), $\alpha$-fetoprotein (AFP) (19), carcinoembryonic antigen (CEA) (20-22), cancer antigen (CA) 125 (23), CA 15-3 (22), and soluble IL-II receptor (sIL2R) (24) were assayed using the CLEIA method. A protein induced by the absence of vitamin K (PIVKA)-II (25) and squamous cell carcinoma-related antigen (SCC-Ag) (26) were assayed using the ECLIA method. C-reactive protein (CRP) (27) was assayed using the Latex turbidimetric immunoassay method. Sialyl Lewis X-i (SLX) (28) and prostate-specific antigen (PSA) (29) were assayed using RIA and CLIA, respectively.

Measurements of immunoglobulin titers, tumor markers, and NK cell activity were entrusted to SRL of a reliable outsourcing company in Japan.

Serum fucoidan levels were assayed using a sandwich ELISA method developed by our laboratory (16). Reproducibility of the fucoidan ELISA method was as follow.

The intra- and inter assay CVs for serum, plasma and urine, using high and low concentration of fucoidan, were in the range of $1.5-13.4 \%$.

Statistical analysis. Statistical analyses were performed using SAS version 9.4 (Statistical Analysis Software 9.4, 

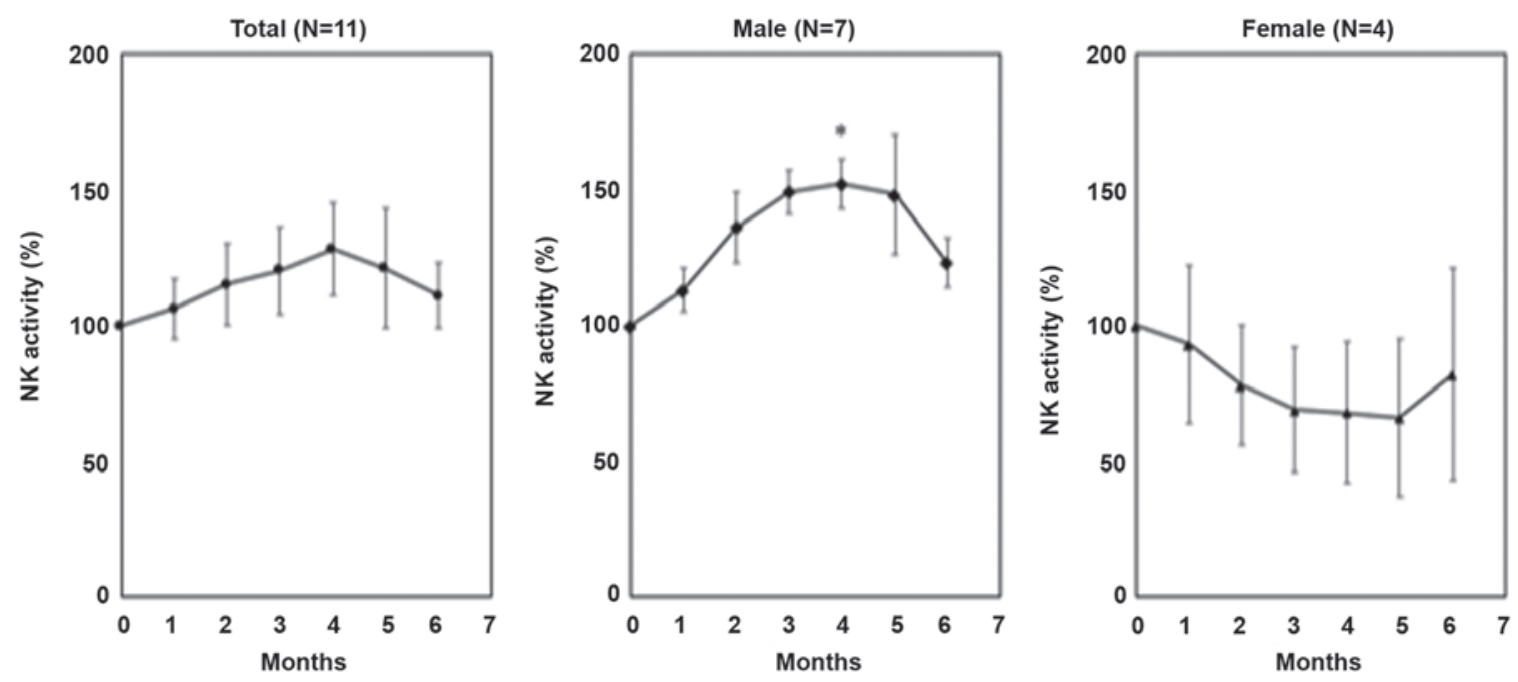

Figure 1. NK cell activity following the ingestion of fucoidan. Due to large variations in the basal NK cell activity (range 5-69\%), variables are expressed as a percentage of relative to basal value (100\%). No significant changes of NK cell activity were shown in total patients (left panel). NK cell activity in male patients was significantly increased at 4 months after fucoidan ingestion compared to the basal value (middle panel). Data were expressed as mean $\pm \mathrm{SE}$. ${ }^{*} \mathrm{P}<0.05$ significantly different from the basal value $(0 \mathrm{M})$. NK, natural killer.

SAS Institute Inc.). Mean quantitative values were compared between the basal value and the value at each time point during the trial period using the Friedman test. Post hoc comparison was performed using the Bonferroni method. Statistical correlation was analyzed using Spearman's rank correlation coefficient. $\mathrm{P}<0.05$ was considered to indicate a statistically significant difference.

\section{Results}

Clinical assessment. No severe adverse effects were observed during the trial period, and all subjects tolerated the ingestion of fucoidan.

Primary outcome. No significant changes were observed in the mean activities of NK cells in total subject between before and after the ingestion of fucoidan. An analysis of each sex revealed that NK cell activity was elevated in seven male subjects, and was significantly different 4 months after than before the ingestion of fucoidan; however, changes in NK cell activity were not significant in four female subjects (Fig. 1).

$\operatorname{IgG}, \operatorname{IgA}$, and $\operatorname{IgE}$ titers remained unchanged during the trial period (Table SI).

According to the result of multiple regression analysis, demographic characteristics of subjects, such as age, height, and body weight were not a significant factor contributing to NK cell activity and immunoglobulins titers (data not shown).

Tumor markers. In Cases 1, 2, 3, 4, 5, 8, and 9, in whom primary tumors were eradicated by surgical resection or RFA, tumor markers remained within the reference range before and after the ingestion of fucoidan. Basal values for tumor markers were elevated in three cases. In Cases 6 and 11, who were receiving chemotherapy, tumor markers slightly decreased in the former, but increased in the latter after the ingestion of fucoidan. Case 7 was awaiting surgery for prostate cancer. PSA levels gradually increased during the trial period (Table III).

Fucoidan absorption. Mean serum fucoidan levels were significantly increased one month and six months following the ingestion of fucoidan; peak levels ranged between 30 and $198 \mathrm{ng} / \mathrm{ml}$. Fucoidan levels did not show a sex difference (Fig. 2).

Clinical laboratory test. Statistical analysis of all subjects indicated that no significant changes were observed in clinical parameters, such as hematology, liver function, renal function, lipids, electrolytes, and the urinalysis, over the trial period (Tables SII and SIII).

Abnormal laboratory parameters before treatment were observed in a few cases. Two patients showed mild elevation of Cr levels, and abnormal $\gamma$-GTP and AST levels were observed in two patients with alcoholic liver injury. AST and ALT levels were elevated temporally in a patient with drug induced liver injury; elevation of AST and ALT levels was within 2 times the upper limit of normal. Renal injury and liver damage were not so severe as to affect the drug metabolism during the trial period.

Correlation among NK cell activity, immunoglobulin titers, and laboratory parameters. NK cell activity positively correlated with albumin and hemoglobin levels; a significant correlation was observed 1 month into the trial. NK cell activity had a significant negative correlation with AST levels $1,3,4$, and 5 months after the ingestion of fucoidan. NK cell activity had a significant negative correlation with ALT levels 4 months into the trial (Fig. 3).

IgG titers did not correlate with laboratory parameters. IgA titers negatively correlated with lymphocyte counts and positively correlated with $\gamma$-GTP levels. IgE titers positively correlated with $\mathrm{Cr}$ and $\gamma$-GTP levels, and negatively correlated with lymphocyte counts (data not shown). 
Table III. Changes of tumor markers after the ingestion of fucoidan.

Tumor marker (reference range)
Male, 67 y.o, pharyngeal cancer, post-surgical resection
CYFRA21-1 $(<5.0 \mathrm{ng} / \mathrm{ml})$

Male, 81 y.o, hepatocellular carcinoma, post-radiofrequency ablation

$\operatorname{AFP}(<10 \mathrm{ng} / \mathrm{ml})$

PIVKA-II ( $<40 \mathrm{mAU} / \mathrm{ml})$

Male, 78 y.o, hepatocellular carcinoma, post-radiofrequency ablation

$\operatorname{AFP}(<10 \mathrm{ng} / \mathrm{ml})$

PIVKA-II $(<40 \mathrm{mAU} / \mathrm{ml})$

Male, 70 y.o, renal cell cancer, post-surgical resection

CRP $(<0.3 \mathrm{mg} / \mathrm{dl})$

Male, 71 y.o, colon cancer, post-surgical resection

CEA $(<5.0 \mathrm{ng} / \mathrm{ml})$

Male, 74 y.o, lung cancer, undergoing chemotherapy

CEA $(<5.0 \mathrm{ng} / \mathrm{ml})$

SLX $(<38 \mathrm{U} / \mathrm{ml})$

Male, 76 y.o, prostate cancer, pre-surgical operation

PSA $(<4.0 \mathrm{ng} / \mathrm{ml})$

Female, 58 y.o, cervical cancer, post-surgical resection

CA125 $(<35.0 \mathrm{U} / \mathrm{ml})$

$\mathrm{SCC}(<2.5 \mathrm{ng} / \mathrm{ml})$

Female, 52 y.o, breast cancer, post-surgical resection

CEA $(<5.0 \mathrm{ng} / \mathrm{ml})$

CA15-3 $(<25.0 \mathrm{U} / \mathrm{ml})$

Female, 56 y.o, colon cancer, post-surgical resection

CEA $(<5.0 \mathrm{ng} / \mathrm{ml})$

Female, 70 y.o, adult T-cell leukemia, undergoing chemotherapy

sIL-2R (154-510 U/ml)

\begin{tabular}{|c|c|c|c|c|c|c|}
\hline 0 & $1 \mathrm{M}$ & $2 \mathrm{M}$ & $3 \mathrm{M}$ & $4 \mathrm{M}$ & $5 \mathrm{M}$ & $6 \mathrm{M}$ \\
\hline $1.0<$ & $1.0<$ & $1.0<$ & $1.0<$ & $1.0<$ & $1.0<$ & $1.0<$ \\
\hline 2.8 & 3.6 & 3.4 & 3.0 & 3.5 & 2.9 & 2.9 \\
\hline 19 & 21 & 16 & 18 & 22 & 23 & 18 \\
\hline 2.6 & 3.0 & 3.2 & 2.7 & 2.9 & 2.8 & 2.5 \\
\hline 25 & 27 & 29 & 28 & 32 & 22 & 27 \\
\hline 0.03 & 0.03 & 0.02 & 0.06 & 0.05 & 0.05 & 0.20 \\
\hline 1.8 & 1.9 & 1.7 & 1.5 & 1.5 & 1.6 & 1.8 \\
\hline 38.2 & 39.7 & 42.2 & 36.4 & 32.3 & 25.7 & 28.5 \\
\hline 51 & 57 & 69 & 57 & 66 & 55 & 55 \\
\hline 2.79 & 3.48 & 3.37 & 4.30 & 4.35 & 4.55 & 4.99 \\
\hline 9.1 & 8.8 & 9.1 & 8.8 & 8.5 & 9.4 & ne \\
\hline 0.9 & 0.7 & 1.1 & 0.8 & 1.0 & 2.2 & ne \\
\hline 2.8 & 2.7 & 2.4 & 2.4 & 2.3 & 2.4 & 2.5 \\
\hline 12.5 & 12.5 & 11.6 & 10.7 & 14.2 & 13.1 & 15.8 \\
\hline 8.1 & 12.1 & 19.0 & 23.4 & 23.0 & ne & ne \\
\hline 4,690 & 10,200 & 13,700 & 9,710 & 10,900 & 12,300 & 11,400 \\
\hline
\end{tabular}

Ne, not examined; y.o, years old.

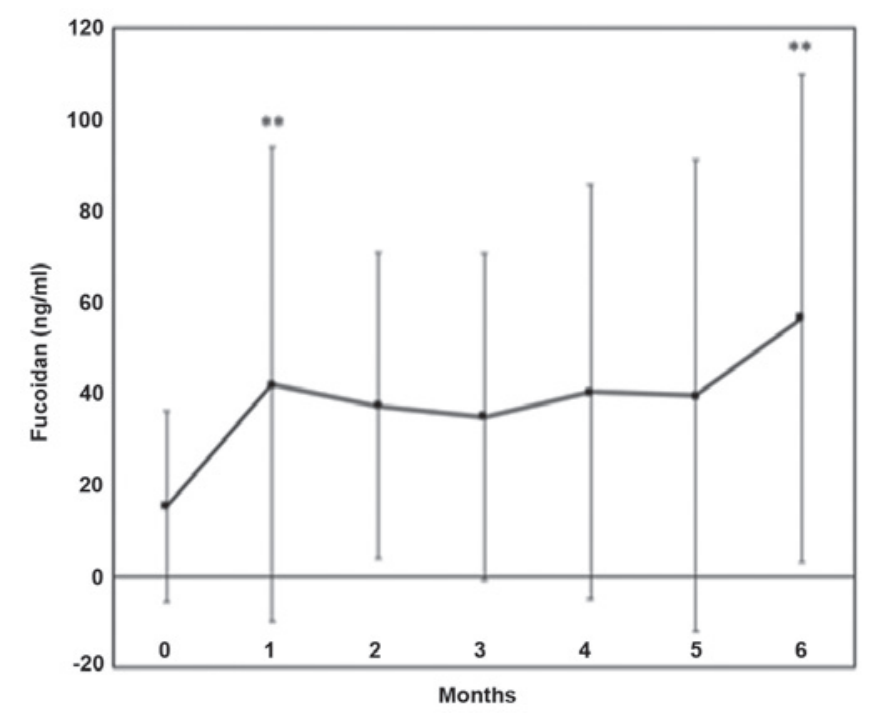

Figure 2. Serum fucoidan levels Serum fucoidan levels were significantly increased one month and six months following fucoidan ingestion compared to the basal value. Data were expressed as mean $\pm \mathrm{SD} .{ }^{* *} \mathrm{P}<0.01$ significantly different from the basal value $(0 \mathrm{M})$.

\section{Discussion}

Numerous in vivo and in vitro studies on the effects of fucoidan on NK cell activity have supported its application as an anticancer drug $(8,9,30,31)$. Regarding in vivo studies on fucoidan, the dose and route of administration were both shown to affect outcomes. Oral intake is more convenient than an intravenous or subcutaneous injection for the administration of fucoidan in clinical settings. Negishi et al reported that the oral administration of $300 \mathrm{mg}$ of Mekabu fucoidan for 24 weeks to elderly subjects receiving influenza vaccines attenuated the aging-related suppression of NK cell activity (32). Based on these findings, we examined the effects of fucoidan on immunomodulation in cancer survivors with a performance status of 0 or 1 . The results obtained demonstrated that fucoidan extracted from C. okamuranus did not increase NK cell activity in total patients, but significantly increased in male cancer survivors. The finding confirmed our unpublished data, in which fucoidan significantly increased NK cell activity in male but not in female healthy volunteers. The mechanism of different function of fucoidan according to sex should be clarified in a future research. 

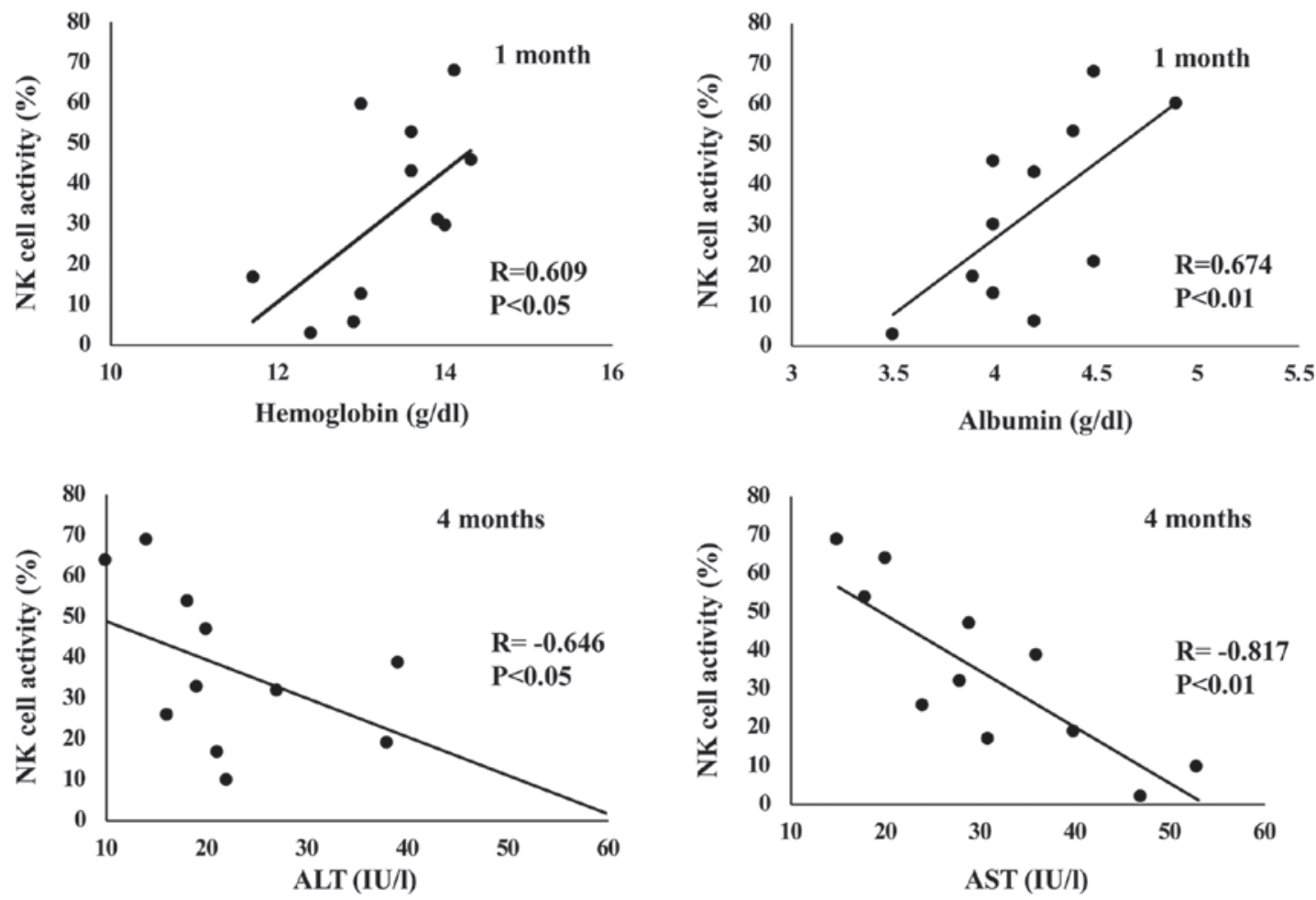

Figure 3. Correlation among NK cell activity and laboratory parameters. NK cell activity had a significant positive correlation with albumin (upper right) and hemoglobin levels (upper left). NK cell activity had a significant negative correlation with AST (lower right) and ALT levels (lower left).

The mechanisms underlying NK cell activation by fucoidan have not yet been elucidated. Cytokines, such as interferon ( $1 \mathrm{FN})-\alpha / \beta, 1 \mathrm{~L}-2,1 \mathrm{~L}-12$, and $1 \mathrm{~L}-15$, activate $\mathrm{NK}$ cells and produce $1 \mathrm{FN}-\gamma$ (33). Since these cytokines were not examined in the present study, further studies are warranted to investigate the role of fucoidan on the induction of NK cell activity by cytokines.

Interestingly, the present study showed that NK cell activity negatively correlated with AST and ALT titers. The percentage of NK cells among liver cells is five times as high as the percentages among spleen or peripheral blood, suggesting that NK cells may play an important role in the immune function of the liver. Accumulating evidences were found that the NK cells were modulated by liver diseases and were further involved in the pathogenesis of liver injury and inflammation (34). Fucoidan was shown to benefit alcohol and non-alcoholic liver disease (3). Taken together with the present and previous studies, fucoidan may activate NK cells via improvement of liver damage through unexplained mechanism.

We evaluated changes in tumor markers caused by the ingestion of fucoidan. In Cases 1, 2, 3, 4, 5, 8, and 9, in whom primary tumors were eradicated by surgery or RFA, tumor markers remained within the reference range before and after the ingestion of fucoidan. These patients increased fucoidan levels and NK cell activity after the ingestion of fucoidan. It is difficult to clarify whether this effect is related to medical intervention or fucoidan administration. Noteworthy, there was no recurrence of the primary tumors in these cases during the trial period. Long-term surveillance in large-scale and well-organized studies is needed to clarify whether fucoidan alone is able to reduce their risk of recurrence via
NK cell activation in male cancer survivors after conventional chemotherapy, radiofrequency ablation or radiotherapy.

Regarding the two cases undergoing conventional chemotherapy, tumor markers were continuously elevated in Case 11 but decreased in Case 6 following the administration of fucoidan. Case 6 taking erlotinib revealed elevation of fucoidan levels and NK cell activity following the ingestion of fucoidan. Case 11 taking irinotecan showed elevation of fucoidan levels and decrease of NK cell activity. It is important to assess the effect of chemotherapeutic regimens on circulating levels of fucoidan and NK cells activity. In addition, the ability of fucoidan as an adjunct therapy during conventional chemotherapy has been reported by a few investigators $(12,13)$; therefore, the advantage of fucoidan as a supplemental therapy in the management of cancer patients is needed to be certified in the future.

Given that subjects were heterogeneous, and heavily treated, it is necessary to assess how the disease itself is affecting circulating levels of fucoidan and therefore levels of NK cells and immunoglobulins. Since fucoidan levels were similar in the recovered cancer patients and the non-recovered cancer patients, the disease itself is unlikely affecting the fucoidan absorption in cancer survivors with performance status 0 or 1 . Whereas, fucoidan enhanced NK activity in the recovered cancer patients, but it did not work in the non-recovered cancer patient. It is a further study whether the disease itself affect the fucoidan metabolism in cancer survivors.

Mean serum fucoidan levels were significantly higher one month and six months after than before the ingestion of fucoidan, even though the intestinal absorption of fucoidan was very low, peaking at $198 \mathrm{ng} / \mathrm{ml}$, in serum. The serum profiles after fucoidan administration varied among patients. This result was consistent with our previous findings $(16,35)$. 
Since subjects continued with the same medicine(s) as before, the potential pharmacokinetic interactions between fucoidan and medicines should be clarified in the future. Mild liver damage was observed in three subjects and mild renal injury was complicated with two subjects. Since these patients showed similar fucoidan levels compared with those without liver and renal injury, the fucoidan metabolism is unlikely to be influenced by mild liver and renal injury.

The oral route is essential for the administration of fucoidan in clinical studies. The maximum dose used heretofore was $6 \mathrm{~g}$ of fucoidan for patients with human t-lymphotropic virus type-1-associated neurological diseases. A previous study reported that four out of 17 subjects developed diarrhea within 1 month of trial initiation (36). Other patients with advanced cancer received $4 \mathrm{~g}$ of fucoidan without adverse effects for six months (12). The present results indicated that since the intestinal absorption of fucoidan was so low, it may be difficult to reach the serum levels needed to directly inhibit cancer cell growth or metastasis in clinical trials with safety dose of fucoidan for cancer survivors. Therefore, further studies are needed to establish the effective serum concentration of fucoidan needed for NK cell activation, tumor inhibition, and anti-angiogenesis activity.

Our preliminary study had some limitations. The number of subjects was small in the present study, with only four females being enrolled. This may have affected the statistical analysis; therefore, further studies are needed to confirm the potential effects of fucoidan on NK cell activity using a large number of subjects. The proinflammatory cytokines, including interleukin-1 $\beta$ (IL-1 $\beta$ ), IL-6, and tumor necrosis factor- $\alpha$ (TNF- $\alpha$ ) were reported to be reduced after fucoidan ingestion (13). Since cancer and inflammatory responses are closely associated, we need to assess the relationship between inflammatory markers and levels of fucoidan and NK cells/immunoglobulins. Lack of measurement of inflammation markers was the limitations of the present study. Subjects took a meal without dietary restriction during the trial period. Since this parameter may affect circulating levels of fucoidan, it may be a limitation of the present study.

The oral administration of $3 \mathrm{~g}$ fucoidan was safe for and tolerated well by cancer survivors. The present results showed that fucoidan extracted from $C$. Okamuranus may enhance the activation of NK cells in male cancer survivors. No recurrence of primary tumors was shown in cancer survivors, in whom primary tumor was eradicated by treatment.

\section{Acknowledgements}

The authors would like to thank Assistant Professor Kenji Nakamura (Takasaki University of Health and Welfare) for his helpful advice on the statistical analysis. In addition, the authors thank Dr. Kazuhiro Ono (Medical doctor of Ono Clinic), Dr. Sanae Takeichi (Medical doctor of Takeichi clinic) and Dr. Hiroto Hoshi (Medical Doctor of Hoshi clinic) for their contributions to clinical management of the participants.

\section{Funding}

No funding was received.

\section{Availability of data and materials}

The datasets used and/or analyzed during the present study are available from the corresponding author on reasonable request.

\section{Authors' contributions}

TN designed the study, contributed to the analysis and interpretation of data, and wrote the initial draft of the manuscript. $\mathrm{KK}, \mathrm{MT}$, and MI contributed to the collection and assembly of data. KN contributed to the analysis and interpretation of data and assisted in the preparation of the manuscript. All authors critically reviewed the manuscript and approved the final version.

\section{Ethics approval and consent to participate}

The Ethics Committee of South Product Co., Ltd. approved the present study (approval no. 16-01). Following an explanation of the study and its aim, written informed consent was obtained from all subjects.

\section{Patient consent for publication}

Not applicable.

\section{Competing interests}

The authors declare that they have no competing interests.

\section{References}

1. Cumashi A, Ushakova NA, Preobrazhenskaya ME, D'Incecco A, Piccoli A, Totani L, Tinari N, Morozevich GE, Berman AE, Bilan MI, et al: A comparative study of the anti-inflammatory, anticoagulant, antiangiogenic, and antiadhesive activities of nine different fucoidans from brown seaweeds. Glycobiology 17: 541-552, 2007.

2. Li B, Lu F, Wei X and Zhao R: Fucoidan: Structure and bioactivity. Molecules 13: 1671-1695, 2008.

3. Fitton JH, Stringer DN and Karpiniec SS: Therapies from fucoidan: An update. Mar Drugs 13: 5920-5946, 2015

4. Senthilkumar K, Manivasagan P, Venkatesan J and Kim SK: Brown seaweed fucoidan: Biological activity and apoptosis, growth signaling mechanism in cancer. Int J Biol Macromol 60: 366-374, 2013.

5. Kwak JY: Fucoidan as a marine anticancer agent in preclinical development. Mar Drugs 12: 851-870, 2014.

6. Wang P, Liu Z, Liu X, Teng H, Zhang C, Hou L and Zou X: Anti-metastasis effect of fucoidan from Undaria pinnatifida sporophylls in mouse hepatocarcinoma Hca-F cells. PLoS One 9: e106071, 2014

7. Wu L, Sun J, Su X, Yu Q, Yu Q and Zhang P: A review about the development of fucoidan in antitumor activity: Progress and challenges. Carbohydr Polym 154: 96-111, 2016.

8. Atashrazm F, Lowenthal RM, Woods GM, Holloway AF, Karpiniec SS and Dickinson JL: Fucoidan suppresses the growth of human acute promyelocytic leukemia cells in vitro and in vivo. J Cell Physiol 231: 688-697, 2016.

9. Zhang W, Oda T, Yu Q and Jin JO: Fucoidan from Macrocystis pyrifera has powerful immune-modulatory effects compared to three other fucoidans. Mar Drugs 13: 1084-1104, 2015.

10. Centers for Disease Control and Prevention (CDC): Cancer survivors-United States, 2007. MMWR Morb Mortal Wkly Rep 60: 269-272, 2011.

11. Rock CR, Doyle C, Demark-Wahnefried W, Meyerhardt J, Courneya KS, Schwartz AL, Bandera EV, Hamilton KK, Grant B, McCullough M, et al: Nutrition and physical activity guidelines for cancer survivors. CA Cancer J Clin 62: 243-274, 2012. 
12. Ikeguchi M, Yamamoto M, Arai Y, Maeta Y, Ashida K, Katano K, Miki Y and Kimura T: Fucoidan reduces the toxicities of chemotherapy for patients with unresectable advanced or recurrent colorectal cancer. Oncol Lett 2: 319-322, 2011.

13. Takahashi H, Kawaguchi M, Kitamura K, Narumiya S, Kawamura M, Tengan I, Nishimoto S, Hanamure Y, Majima Y, Tsubura S, et al: An exploratory study on the anti-inflammatory effects of fucoidan in relation to quality of life in advanced cancer patients. Integr Cancer Ther 17: 282-291, 2018.

14. Whiteside TL and Herberman RB: The role of natural killer cells in human disease. Clin Immunol Immunopathol 53: 1-23, 1989.

15. Imai K, Matsuyama S, Miyake S, Suga K and Nakachi K: Natural cytotoxic activity of peripheral-blood lymphocytes and cancer incidence: An 11-year follow-up study of a general population. Lancet 356: 1795-1799, 2000

16. Tokita Y, Nakajima K, Mochida $H$, Iha $M$ and Nagamine $T$ : Development of a fucoidan-specific antibody and measurement of fucoidan in serum and urine by sandwich ELISA. Biosci Biotechnol Biochem 74: 350-357, 2010.

17. Oshimi K, Oshimi Y, Satake M and Mizoguchi H: Natural killer-mediated lysis of normal and malignant target cells, and its regulation by monocytes. J Exp Med 162: 472-486, 1985.

18. Alkotyfan K, Wiegand S, Müller HH, Windfuhr JP, Werner JA and Sesterhenn AM: Cyfra 21-1 as a tumor marker for follow-up of patients with squamous cell carcinoma of the oropharynx. Anticancer Res 30: 2291-2296, 2010.

19. Aoyagi Y: Carbohydrate-based measurements on alpha-fetoprotein in the early diagnosis of hepatocellular carcinoma. Glycoconj J 12: 194-199, 1995

20. Das V, Kalita J and Pal M: Predictive and prognostic biomarkers in colorectal cancer: A systematic review of recent advances and challenges. Biomed Pharmacother 87: 8-19, 2017.

21. Triphuridet N, Vidhyarkorn S, Worakitsitisatorn A, Sricharunrat T, Teerayathanakul N, Auewarakul C, Chungklay N, Krongthong W, Luengingkasoot S, Sornsamdang G, et al: Screening values of carcinoembryonic antigen and cytokeratin 19 fragment for lung cancer in combination with low-dose computed tomography in high-risk populations: Initial and 2-year screening outcomes. Lung Cancer 122: 243-248, 2018

22. LiX, DaiD, Chen B, Tang H,Xie X and Wei W: Clinicopathological and prognostic significance of cancer antigen 15-3 and carcinoembryonic antigen in breast cancer: A meta-analysis including 12,993 patients. Dis Markers 2018: 9863092, 2018.

23. Laengsri V, Kerdpin U, Plabplueng C, Treeratanapiboon L and Nuchnoi P: Cervical cancer markers: Epigenetics and microRNAs. Lab Med 49: 97-111, 2018.

24. Umekita K, Hashiba Y, Kariya Y, Kubo K, Miyauchi S, Aizawa A, Umeki K, Nomura H, Kawaguchi T, Matsuda M, et al: The time-sequential changes of risk factors for adult T-cell leukemia development in human T-cell leukemia virus-positive patients with rheumatoid arthritis: A retrospective cohort study. Mod Rheumatol 29: 795-801, 2019.

25. Xia J, Song P, Sun Z, Sawakami T, Jia M and Wang Z: Advances of diagnostic and mechanistic studies of $\gamma$-glutamyl transpeptidase in hepatocellular carcinoma. Drug Discov Ther 10: 181-187, 2016.
26. Charakorn C, Thadanipon K, Chaijindaratana S, Rattanasiri S, Numthavaj $\mathrm{P}$ and Thakkinstian A: The association between serum squamous cell carcinoma antigen and recurrence and survival of patients with cervical squamous cell carcinoma: A systematic review and meta-analysis. Gynecol Oncol 150: 190-200, 2018

27. Teishima J, Ohara S, Shinmei S, Inoue S, Hayashi T, Mochizuki H, Mita K, Shigeta M and Matsubara A: Normalization of C-reactive protein levels following cytoreductive nephrectomy in patients with metastatic renal cell carcinoma treated with tyrosine kinase inhibitors is associated with improved overall survival. Urol Oncol 36: 339.e9-339.e15, 2018.

28. Mizuguchi S, Nishiyama N, Iwata T, Nishida T, Izumi N, Tsukioka T, Inoue K, Uenishi T, Wakasa K and Suehiro S: Serum sialyl Lewis $\mathrm{x}$ and cytokeratin 19 fragment as predictive factors for recurrence in patients with stage I non-small cell lung cancer. Lung Cancer 58: 369-375, 2007.

29. Stephan C, Jung K, Lein M, Sinha P, Schnorr D and Loening SA Molecular forms of prostate-specific antigen and human kallikrein 2 as promising tools for early diagnosis of prostate cancer. Cancer Epidemiol Biomarkers Prev 9: 1133-1147, 2000.

30. Ale MT, Maruyama H, Tamauchi H, Mikkelsen JD and Meyer AS: Fucoidan from Sargassum sp. and fucus vesiculosus reduces cell viability of lung carcinoma and melanoma cells in vitro and activates natural killer cells in mice in vivo. Int J Biol Macromol 49: 331-336, 2011.

31. Azuma K, Ishihara T, Nakamoto H, Amaha T, Osaki T, Tsuka T, Imagawa T, Minami S, Takashima O, Ifuku S, et al: Effects of oral administration of fucoidan extracted from Cladosiphon okamuranus on tumor growth and survival time in a tumor-bearing mouse model. Mar Drugs 10: 2337-2348, 2012.

32. Negishi H, Mori M, Mori H and Yamori Y: Supplementation of elderly Japanese men and women with fucoidan from seaweed increases immune responses to seasonal influenza vaccination. J Nutr 143: 1794-1798, 2013.

33. Fehniger TA, Shah MH, Turner MJ, VanDeusen JB, Whitman SP, Cooper MA, Suzuki K, Wechser M, Goodsaid F and Caligiuri MA: Differential cytokine and chemokine gene expression by human NK cells following activation with IL-18 or IL-15 in combination with IL-12: Implications for the innate immune response. J Immunol 162: 4511-4520, 1999.

34. Liu P, Chen L and Zhang H: Natural killer cells in liver disease and hepatocellular carcinoma and the NK cell-based immunotherapy. J Immunol Res 2018: 1206737, 2018.

35. Nagamine T, Hayakawa K, Nakazato K and Iha M: Determination of the active transport of fucoidan derived from Okinawa Mozuku across the human intestinal Caco- 2 cells as assessed by size-exclusion chromatography. J Chromatogr B Analyt Technol Biomed Life Sci 997: 187-193, 2015.

36. Araya N, Takahashi K, Sato T, Nakamura T, Sawa C, Hasegawa D, Ando H, Aratani S, Yagishita N, Fujii R, et al: Fucoidan therapy decreases the proviral load in patients with human T-lymphotropic virus type-1-associated neurological disease. Antivir Ther 16: 89-98, 2011. 